\title{
THE MANAGEMENT OF COR PULMONALE
}

\author{
By J. F. Goodwin, M.D., M.R.C.P.
}

Physician and Lecturer in Medicine, Postgraduate Medical School of London

Pulmonary heart disease (cor pulmonale) may be divided into acute, subacute, and chronic types (Wood, 1950; McMichael, 1948). The acute type is typified by massive pulmonary embolism, and will be considered first.

\section{Massive Pulmonary Embolism}

Many pulmonary emboli cause little or no circulatory disturbance, but when a large embolus obstructs the bifurcation of the main pulmonary artery, or multiple emboli obstruct more than two thirds of the peripheral branches, acute pulmonary heart disease results. Acute right ventricular failure ensues, and left ventricular filling is impaired, which results in arterial hypotension, and a fall in cardiac output. The objects of treatment are to encourage the embolus to move on, to prevent additive thrombosis, and to support the failing right ventricle and systemic circulation. Since the systemic blood pressure is usually low, the patient should be nursed flat. Oxygen should be administered and, in very severe cases, respiration may require stimulation by Nikethamide (2.5 to $5 \mathrm{ml}$. intravenously) or Aminophylline ( 0.24 to $0.48 \mathrm{~g}$. intravenously). Persistent arterial hypotension, with systolic levels below 70 to $80 \mathrm{~mm} . \mathrm{Hg}$ may require treatment with pressor amines. A successful outcome has been reported following the use of a slow intravenous infusion of 1-nor-adrenalin (laevophed) (4 mg. dissolved in I litre of dextrose) (Wolff, I954), but the use of sympatheticomimetic drugs is open to the objection that they may cause pulmonary, as well as peripheral, vasoconstriction (Besterman, I95I), and so further embarrass the right ventricle. It is wise, therefore, to withhold l-nor-adrenalin, or similar drugs, unless all other measures fail to produce clinical improvement. The failing right ventricle, meanwhile, can be supported by digitalis, and a full dose of digoxin ( 1 to $1.5 \mathrm{mg}$.) or of strophanthus ( 0.5 to I mg.) should be given intravenously, provided the patient has not previously been taking digitalis. Thereafter, digitalis should be continued in maintenance dosage until all signs of right ventricular failure have disappeared. The suggestion has been made that the raised venous pressure may be compensa $\overrightarrow{0}$ tory in pulmonary embolism, assisting auricular $\vec{F}$ filling and thus maintaining cardiac output, so that agents which lower venous pressure might, there fore, not be of value (Wood, I947). It is very doubtful if this is a practical consideration w however, since digitalis primarily acts by increasingw the strength of ventricular contraction, and thes benefit of this action would outweigh any possibleio disadvantage resulting from direct lowering of venous pressure. Additive thrombosis, or further? emboli, must be discouraged by anticoagulants. $\pi$ Heparin, which acts rapidly, should be given in the early stages of the illness $(50 \mathrm{mg} .4$ to 6 hourly intravenously) as single injections or via a Gordh needle and adaptor. This should be continusd until the effect of an oral anticoagulant of the Coumarin series becomes manifest. Ethyl ba coumacetate (Tromexan) in an initial dose 900 to $1,200 \mathrm{mg}$. and a maintenance dose of 300 tos $600 \mathrm{mg}$. daily, or Phenylindanedione (Dindevan) in an initial dose of 150 to $200 \mathrm{mg}$. and a daily? maintenance dose of 25 to $100 \mathrm{mg}$. should be given at the same time as the first dose of heparin, or aso soon as the patient can take it by mouth. Such? anticoagulant therapy must be controlled by frequent prothrombin times, and should be continued for at least three weeks.

When severe pain or restlessness are important. features, sedatives may be necessary, but morphine 3 should not be given if respiratory failure threatens, and under no circumstances administered to 3 patients with chronic pulmonary disease, asthma, 0 or severe thoracic deformities. Pethedine $(50$ to $100 \mathrm{mg}$.) causes less respiratory depression, but is less effective than morphine in relieving anxiety. and restlessness. The use of atropin, to prevento dangerous vagal reactions, and of papaverine, ton dilate the pulmonary vasculature, has been recom-ñ mended (Wolff, I952), but in the author's opinion they are not of striking value. Pulmonary embolectomy (Trendelenberg operation) is a desperate measure which is seldom now practised.

The prophylaxis of acute pulmonary embolism and of its recurrence lies principally in the prevention of peripheral venous thrombosis, since 
approximately 80 per cent. of emboli arise from this source (Belt, I939). Elderly patients confined to bed may develop a deep calf vein thrombosis insidiously, the first indication being a pulmonary embolism. This is especially true of patients with congestive cardiac failure, or with a fixed low cardiac output. The pelvic veins may also be a source of embolism. Daily leg exercises help to prevent local thrombosis and the routine use of elastic stockings has been advised (Wilkins et al., 1952). Daily examination of the calves should be made. The presence of tenderness, swelling, or a positive Homan's sign, indicate the need for anticoagulants, which reduce the tendency to further thrombosis and to embolisation (Allen et al., 1946). Repeated pulmonary emboli despite adequate anticoagulant therapy may require ligation of the inferior vena cava, but this should only be considered as a last resort.

\section{Subacute Cor Pulmonale}

Subacute cor pulmonale is a form of rapidly progressive pulmonary heart disease due to blocking of the pulmonary circulation by small vascular or tumour emboli, or by miliary lymphatic carcinomatosis (McMichael, I948; Wood, 1950).

\section{Chronic Cor Pulmonale}

Chronic cor pulmonale may be classified in the following way: (Modified from McMichael, r948, and Wood, I950).

I. Obstructive

Specific forms of pulmonary arteritis

Idiopathic pulmonary hypertension

Recurrent pulmonary emboli

In this group a progressive reduction in the pulmonary vascular bed and an increase in pulmonary vascular resistance, due to obstructive lesions in the small vessels, produce failure of the right ventricle.

2. Anoxic

Chronic bronchitis

Emphysema

Pulmonary fibrosis

Bronchietasis

Cystic disease

Tuberculosis

Pheumoconiosis

(Kyphoscoliosis).

The diseases in this group (when severe enough to cause pulmonary heart disease) all have the common features of impaired pulmonary function, anoxia, and carbon dioxide retention.

Pulmonary hypertension (of varying degree) is a constant finding in both groups, resulting in the first from obstruction to the pulmonary circulation, and in the second from anoxia, obliteration of the pulmonary vascular bed by pulmonary fibrosis or emphysema and from other factors not yet fully understood.

The commonest cause of chronic cor pulmonale is severe emphysema and bronchitis, and the management of this condition will be considered in detail. Treatment both of the acute phase of cor pulmonale supervening on chronic lung disease, and of the subsequent management and prevention of further exacerbations, must be considered.

The development of a pulmonary infection in a subject with chronic lung disease sets in motion a train of events which may result in respiratory and cardiac failure. The effect of emphysema and chronic bronchitis is to produce impedance to the flow of air in and out of the lungs, uneven ventilation of the alveoli, and uneven distribution of the blood through the lungs. An attack of acute bronchitis intensifies these abnormalities and results in further anoxia and carbon-dioxide retention. This results in pulmonary hynertension, hypervolaemia, polycythaemia, and an increase in cardiac output (Harvey et al., I95 I). Such patients have a relatively high cardiac output (McMichael, 1948) with central cyanosis, raised jugular venous pressure, warm extremities, and a bounding arterial pulse. Further anoxia and right ventricular insufficiency will then lead to a progressive fall in cardiac output in the terminal phase of the disease.

Treatment should be directed towards combatting the pulmonary infection, reducing the anoxia, and supporting the right ventricle.

\section{Treatment of the Pulmonary Infection}

Adequate chemotherapy at the earliest possible moment is of the greatest importance (Simpson, 1954). At least 2 mega units per day of crystalline penicillin should be given in divided doses 4-hourly, after a sample of sputum has been obtained for bacteriological examination. If an immediate response is not obtained, alternative antibiotics should be used and, if time permits, the sensitivity of the organisms in the sputum should be determined. May (1953) has shown that the most important organisms in chronic bronchitis are Haemophilus influenzae and the pneumococcus. These bacteria are also likely to be present in acute exacerbations (Flint, 1954). Chloramphenicol may be effective against Haemophilus influenzae, but the danger of toxic effects on the bone marrow, especially after repeated courses, should discourage its use. Streptomycin is effective but its use as the sole antibiotic encourages the emergence of resistant organisms, and may also make subsequent diagnosis difficult if there is a tuberculous lung infection. If employed, streptomycin should be given in high dosage for a short period ( 2 to $3 \mathrm{~g}$./day for 4 to 5 
days). In the seriously ill patient, the combination of penicillin and streptomycin is probably the most satisfactory, but in less severe cases, tetracycline, chlortetracyclin (aureomycin), or oxytetracycline (terramycin), in a dosage of $25^{\circ} \mathrm{mg}$. 6-hourly, can also be effective. They should not be given for long periods because of the risk of gastro-intestinal disturbance and fungus infections of the lung. Whenever possible, however, the sensitivity of the organisms in the sputum should dictate the choice of antibiotic. While early and adequate chemotherapy may do much to alleviate anoxia, other factors tend to perpetuate it. There is often swelling of the bronchial mucosa with blocking of the swollen air passages with tenacious sputum, and sometimes bronchospasm. Bronchodilators such as ephedrine or isopropylnoradrenalin (isoprenalin) should be used, an effective solution for use in a nebuliser or Collison inhaler being Neb. Isoprenaline Co. (N.F.). Attempts have been made (mainly in children with acute bronchitis) to liquefy tenacious sputum by the use of aerosol detergents, such as 'Alevaire' (Gans, I954). Such aerosols must be administered by a nebuliser (such as the Oxygenaire Vaporiser) capable of producing particles no larger than $3 \mu$ in diameter. Further work is necessary to determine the value of aerosols in the treatment of acute respiratory infections, but the old fashioned inhalations of friar's balsam may sometimes be effective in loosening tenacious sputum. Coughing and breathing exercises, and vigorous chest percussion are also of value (Westlake, 1954). Bronchoscopic aspiration of tenacious bronchial secretions has been recommended by Westlake $e t$ al. (I955), if simpler methods fail to dislodge them, but many patients are not fit for bronchoscopy, which in any event will not drain the smaller air passages.

\section{Treatment of Respiratory Failure}

One of the most important complications of acute or chronic cor pulmonale is respiratory failure. Patients with severe lung disease have a reduced maximum ventilatory capacity, which leads to carbon dioxide retention and anoxaemia. Scott (1920) has shown that in emphysema the normal respiratory response to carbon dioxide is reduced, and that hypercapnoea depresses the respiratory centre, the normal stimulus to respiration being provided by the low arterial oxygen saturation. Such severely anoxic patients have a respiratory acidosis, with shallow ineffective respirations. The failing respiratory centre should be stimulated by large doses of nikethamide ( 10 to I $5 \mathrm{ml}$.) intravenously (Westlake et al., 1955). Mechanical stimulation of respiration has not proved of great value (Westlake, 1954), although
Boutourline-Young and Whittenberger (195 I) ando Stone et al. (1953) have had some success with å Drinker type of respirator. Nevertheless, if 3 respiration fails, manual artificial respiration $\mathbb{\perp}$ should be performed until respiratory stimulants. $C$ and oxygen can produce an effect.

The use of morphine is absolutely contraindicated in cor pulmonale, its depressant effect $\frac{}{2}$ upon the respiratory centre being lethal. This is $\frac{\bar{c}}{\mathrm{c}}$ also true in kyphoscoliotic heart disease (Daley, $\overrightarrow{\mathbb{D}}$ 1945). Should morphine have been given, how- 2 ever, its effects can be reversed by the use of the morphine antagonist, $\mathrm{N}$-allyl-nor-morphine $\vec{\circ}$ (Nalorphine. Lethedrone) (10 mg. intravenously) (Eckenhoff et al., 1952), although it must be administered quickly (Westlake, I954).

\section{The Place of Oxygen Therapy}

Patients with severe anoxic cor pulmonale are frequently drowsy and irrational and may exhibito muscular twitchings. A raised cerebrospinal ${ }_{i}^{+}$ fluid pressure is not uncommon, and papilloedema ${ }^{\infty}$ may occur (Simpson, 1954). Westlake and Kaye 3 (1954) have shown that the increase in intra- $\vec{T}$ cranial pressure is the result of anoxia and hyper- $-\mathbb{D}$ capnoea which produces cerebral vasodilatation.

The neurological manifestations are the direct? result of acidaemia and hypercapnoea on the cerebrum (Westlake et al., 1955). Oxygen therapye in such patients may exacerbate these symptoms, and even produce coma (Davies and MacKinnomir. 1949), and respiratory failure, since the responses of the respiratory centre to carbon dioxide iso diminished, and anoxia is the main stimulus too respiration (Harvey et al., 195I).

Oxygen must, therefore, be administered with $\overrightarrow{\bar{O}}$ great caution, careful observation being necessary 3 to detect impending respiratory failure, and the? development of neurological signs, or of coma. Harvey et al. (1953) recommended that the carbono dioxide content of the arterial blood should always be estimated before starting oxygen therapy, but? while highly desirable, this is not always practicable, and lack of suitable facilities for this? investigation should not prohibit the use of oxygen.

Oxygen should be given initially by nasal catheters, B.L.B. mask, or lightweight B.O.C. 'polymask,' at a rate of I to 3 litres $/ \mathrm{min}$. This slow rate of flow produces only partial relief of anoxaemia, but avoids a rapid and considerable rise of arterial carbon-dioxide tension (Simpson 1954; Westlake, 1954; Westlake et al., 1955). Oxygen may also be administered in a tent, the patient being allowed to breathe room air for tere minutes in every hour (Donald, 1953). Simpsone (1954) considers the threat of coma to be of greater importance than the relief of cyanosis, and any impending signs of the former should indicate 




FIG. 1.-Postero anterior chest radiograph of a patient with congestive cardiac failure due to chronic bronchitis and emphysema. There is considerable cardiac enlargement involving mainly the right auricle, right ventricle, and pulmonary arteries.

a reduction in the flow rate of oxygen, even though the latter is severe.

It should be stressed that although the dangers of oxygen are appreciable in cor pulmonale, they can be overcome by meticulous observation and management, and that the benefits of oxygen therapy when properly used are so great that no patient should be denied it.

\section{The Treatment of Congestive Heart Failure in Cor Pulmonale}

As has been stated, the initial stages of acute pulmonary heart failure are associated with a hyperdynamic circulation: rapid, bounding pulse, warm extremities and raised venous pressure, with hepatic enlargement and often peripheral oedma (McMichael, I948). The treatment of this stage is still somewhat controversial. It is possible that the raised venous pressure is compensatory, and helps to keep the cardiac output at a level necessary to keep the tissues supplied with oxygen. Howarth et al. (1947) found that digitalis and venesection produced a decrease in cardiac output in these circumstances, and McMichael (I948) advised against the use of digitalis or venesection.

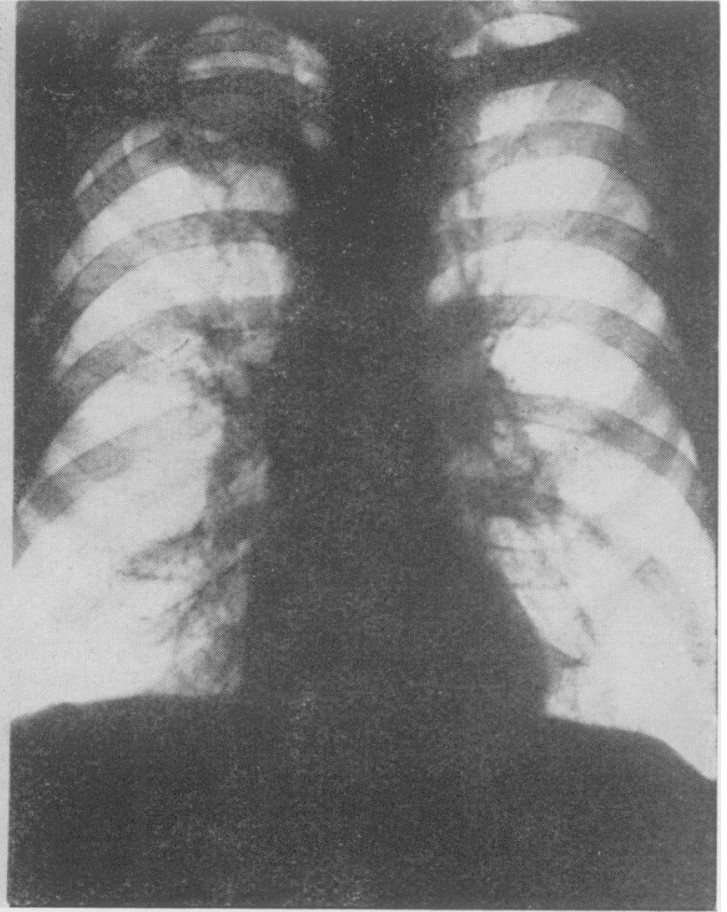

FIG. 2.-Postero anterior chest radiograph of the same patient after relief of acute respiratory infection and cardiac failure. There is a considerable reduction in heart size, although the pulmonary arteries remain enlarged.

Furthermore, the action of digitalis upon ventricular function in these patients is not always predictable. Gray et al. (1952) gave intravenous digitalis to nine patients with cor pulmonale and found that in two the work of the heart increased, while in only three was any clinical benefit noted. Ferrer et al. (1950) found an increase in right ventricular pulse pressure, and a slight rise in output in similar patients, while Mounsey et al. (1952) obtained the same results, but without any rise in output. Both groups of workers found that the pulmonary artery pressure rose slightly after digitalis. Although the effect of digitalis is unlikely to be as dramatic as in left ventricular failure, its use may do good and is unlikely to do harm. It should be remembered, however, that the most important aspect of therapy is the relief of anoxia. Mounsey et al. (1952) have shown that the pulmonary artery pressure rises during an attack of failure, and falls when the failure is under control. High pulmonary artery pressures are associated with low arterial oxygen saturations, and when anoxia has been relieved the pulmonary arterial pressure falls, the work of the right ventricle is lessened, and the failureresolves. The relief of cardiac failure is well illustrated in 
Figs. I and 2, which show a remarkable reduction in heart size after recovery from an attack of pulmonary heart failure. The reduction in right ventricular stress is also well shown cardiographically (Figs. 3 and 4) (Mounsey et al., I952a; Camerini et al., 1955).

Venesection is not now frequently practised, but its value has been stressed in patients with marked polycythaemia and vascular engorgement (Donald, 1953). Aminophyllin 0.24 to 0.48 g. in ro c.c. sterile water as an intravenous injection may be of great help in reducing bronchospasm, stimulating ventricular contraction and the respiratory centre, and acting as a mild diuretic. In patients with marked oedema, mercurial diuretics are needed, and in any event, the patient should be placed on a low salt diet. The use of acetazoleamide (Diamox) in the treatment of acute respiratory acidosis has been reported by various workers (Nadell, I953; Wishart and Isaacs, 1955). Acetazoleamide inhibits the enzyme carbonic anhydrase, the main action being upon the renal tubules, producing increased excretion of sodium, potassium, and bicarbonate, reduced ammonia excretion, a reduction in serum bicarbonate level and blood $\mathrm{pH}$, and a rise in urinary $\mathrm{pH}$ (Nadell, I953; Counihan et al., 1954). Both the fall in blood bicarbonate and the increased sodium excretion and diuresis might be expected to be beneficial in acute cor pulmonale. Nadell (1953) reported encouraging results in six cases, and thought that carbon dioxide removal by the lungs seemed to be more effective after acetazoleamide, while Bell et al. (1955) also comment favourably on the use of this drug in respiratory disorders. Wishart and Isaacs (1955) point out, however, that increased removal of carbon dioxide by the lungs is unlikely to occur in a subject with grossly impaired ventilatory function and a respiratory centre already insensitive to the stimulus of hypercapnoea, and that the urinary loss of bicarbonate would tend to lower further the blood $\mathrm{pH}$, which would be harmful in an acidotic state. They treated three patients with acute respiratory acidosis with acetozoleamide; all three cases deteriorated, two died and one recovered after the drug was withdrawn.

It is doubtful, therefore, whether acetozoleamide should be given to patients with severe respiratory acidosis.

In severe cases in which signs of cadiac failure persist despite energetic therapy, some benefit may be obtained from reducing metabolism and oxygen requirements, by depression of the thyroid gland (Sharpey-Schafer, I946). Ablation with radio-active iodine may be attempted, or antithyroid drugs, such as neomercazole, administered. The latter must be given in full dosage

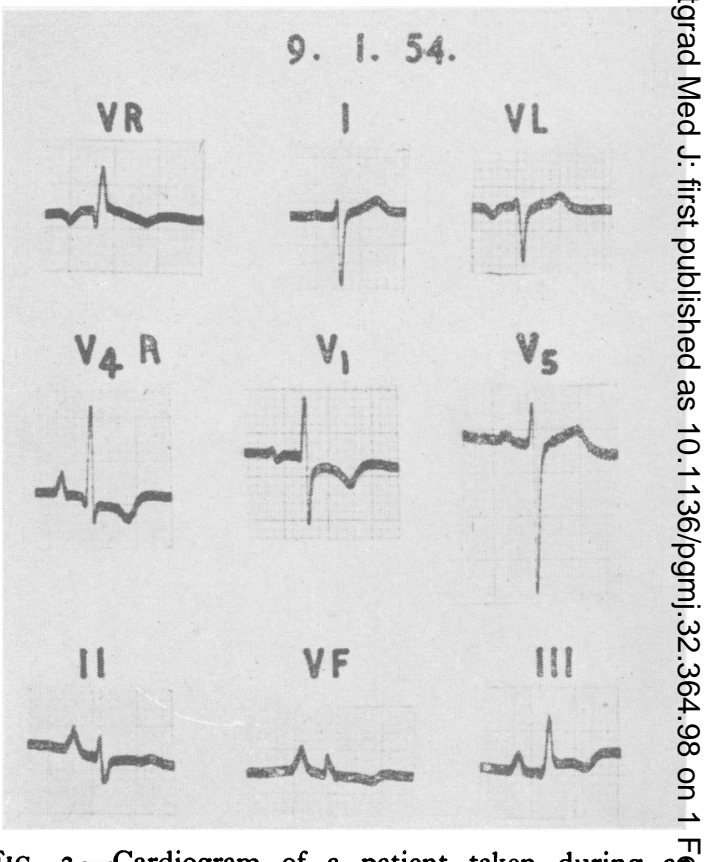

FIG. 3.-Cardiogram of a patient taken during â exacerbation of pulmonary heart failure. There evidence of right ventricular hypertrophy, shown by the dominant $R$ wave in leads $V_{4} R$ and $V R$, the $R$ pattern in $V_{5}$, and the augmented $P$ waves of right auricular enlargement.

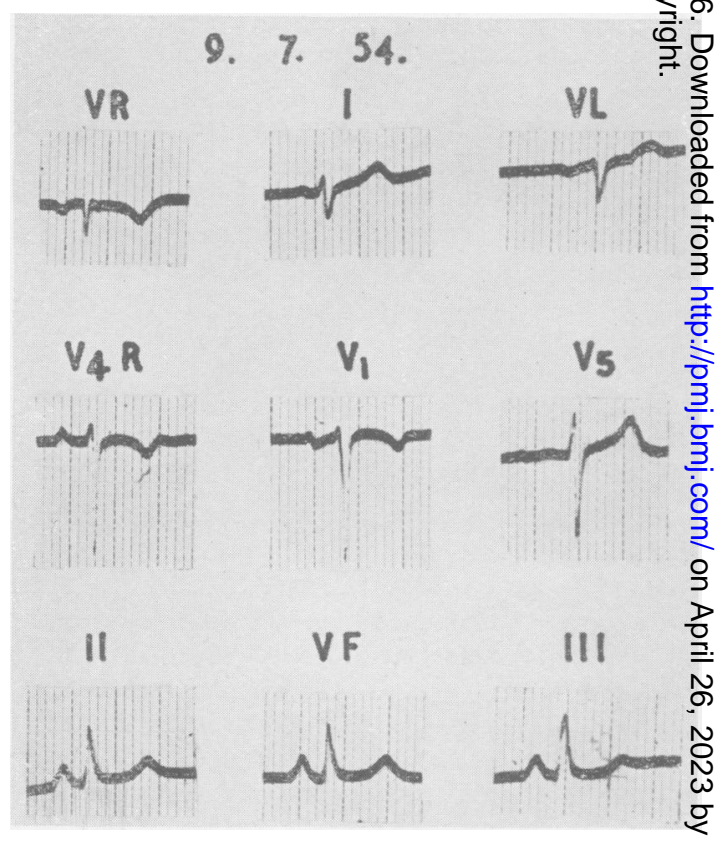

FIG. 4.-Cardiogram of the same patient six month later, after recovering from cardiac failure. Th甲 only evidence of right ventricular enlargement which remains is the $r S$ complex in lead $V_{50}$ Leads $V_{4} R$ and $V R$ are normal and the $R$ wave io $V_{1}$ has greatly decreased in size. 
over long periods to achieve any result, which is often not dramatic.

\section{The Treatment of Pulmonary Hypertension}

In many patients, as has been said, the pulmonary artery pressure returns to normal after recovery from an acute attack of respiratory infection and anoxia. In some, however, pulmonary hypertension persists, either because of obstruction to the small lung vessels (obstructive cor pulmonale) or because of persistent anoxia and destruction of lung substance by severe pulmonary disease. Progressive failure of the right ventricle is likely to follow, unless the pulmonary vascular resistance can be reduced. Fowler et al. (1950) have shown that ganglion blocking agents may produce pulmonary arteriolar dilatation and reduction in pulmonary artery pressure. Davies et al. (1954) showed that hexamethonium bromide produced a fall in pulmonary artery pressure in patients with severe pulmonary hypertension due to mitral stenosis, and considered that the drug probably produced its effect by blocking vasoconstrictor impulses to the pulmonary vasculature. Whiteside and Coigley (1952) reported favourably on the use of hexamethonium in patients with cor pulmonale, and personal experience has shown that this drug can reduce the pulmonary vascular resistance in this condition. Ganglion blocking agents are worthy of trial in patients with persistent pulmonary hypertension, and may also be of value in relieving bronchospasm although it should be remembered that they block sympathetic as well as parasympathetic impulses, and might therefore actually increase spasm.

Imidazoline (Tolazoline) (Priscol), which has been of value in idiopathic pulmonary hypertension (Dresdale et al., 1951), may also be tried.

\section{Steroid Hormones in Chronic Pulmonary Disease}

Cortisone or ACTH have been used in patients with chronic pulmonary fibrosis but the results are variable (West et al., 195 I ; Galdston et al., 195I). If there is persistent and severe bronchospasm which does not respond to the usual methods of treatment, ACTH may be lifesaving (Bordley et al., 1949). ACTH may be administered slowly by intravenous drip, or ACTHAR gel may be given intramuscularly ( 20 to 80 units b.d.). Unfortunately, withdrawal of the drug may be followed by relapse. Patients with any evidence of heart failure who are receiving ACTH should be on a low sodium diet with potassium supplements, and mercurial diuretics may be required. Adequate antibiotic cover is essential.

The long term treatment of severe asthma has been reported by Ball (1954), and by Savidge and
Brockbank (1954), with variable results, but the latter authors point out that cortisone is not without risk in these patients, two of whom died unexpectedly (Savidge and Brockbank, 1954). Very recently, Davies and Williams (I955) have reported somewhat more encouraging long term results with hormone therapy.

\section{After-care and the Prevention of Acute Respiratory Infections}

The importance of prevention of further attacks of respiratory infection, with their attendant risks to the chronic bronchitic cannot be stressed too strongly. Simpson (1954) recommends the use of breathing exercises, and most patients can be taught to do them. The onset of even an apparently trivial ' cold' or upper respiratory infection should be treated seriously. The patient should remain in a warm, humid atmosphere. The effect of cold and fog is particularly to be feared (Brit. med. F., 1954), (Elmes et al., 1953), (Lancet, 1953), and a satisfactory ' smog' mask is urgently required. The early administration of chemotherapy may prevent a serious respiratory infection, although the choice of drug is difficult. Kilpatrick and Oldham (1954) conducted a clinical trial of continuous sulphonamide therapy during the winter in patients with chronic bronchitis, but failed to produce any evidence that these drugs prevented acute exacerbations. Elmes et al. (1953) observed the effects of penicillin, sulphadimidine, aureomycin, and chloramphenicol on the sputum in a group of chronic bronchitics. Each drug, except sulphadimidine, reduced the bacterial counts, and the purulence of the sputum, but the clinical effects were slight. The most satisfactory antibiotic may prove to be Tetracycline (Fletcher, 1955). In practice, however, the early use of adequate doses of penicillin, combined with the general measures outlined above, and with expectorants or inhalation of friar's balsam to encourage expectoration, may do much to avert a serious attack. Bronchodilators should be used if there is any evidence of spasm. Smoking should be reduced or discontinued, as the incidence of bronchitis is higher in smokers than non-smokers (Palmer, 1954).

The importance of infection in the production of heart failure in chronic respiratory disease has been stressed by Flint (1954), and the magnitude of the problem is such that the energetic investigation and treatment of chronic bronchitis is of the greatest urgency.

\section{BIBLIOGRAPHY}

ALLEN, E. V., BARKER, N. W. and HINES, E. A. (1946), 'Peripheral' Vascular Diseases,' Philadelphia and London, W. B. Saunders, p.639.

Bibliography continued on page 110. 
because the book is directed towards an extramedical readership, but many doctors will feel a sense of loss in the absence of a critical evaluation of available therapeutic methods which Dr. Hamilton is obviously well fitted to provide. Despite this omission, there can be little doubt that this work represents the most useful contribution to psychosomatic medicine which the past year has offered. The references are relevant yet wide in scope, the style is authoritative yet eminently readable, and the author has put considerable work into the task of assessing statistically the often vague and high generalized results so common in the earlier papero. 'Psychosomatics' will be appreciated as much within the medical profession as in the scientif circles for whom it has been written, not only for the information it contains, but also for the higi standard of medical authorship which it reflects.

\section{'DRINAMYL SPANSULE' CAPSULES}

Smith Kline \& French International Co., represented by Menley \& James, Limited, Coldharbour Lane, London, S.E.5, announce the introduction of 'Drinamyl Spansule' capsules. Taken on rising one capsule affords day-long control of worry and harassment. By presenting 'Drinamyl,' already widely used and recom- mended for this purpose, in 'Spansule' form, the patient's mood is kept stable throughout the dayiw

When prescribing it is important to specify the strength required: Strength No. I contains ro mgo 'Dexedrine ' and $65 \mathrm{mg}$. amylobarbitone; Strengtlp No. 2 contains $15 \mathrm{mg}$. 'Dexedrine' and $97 \mathrm{mg}$. amylobarbitone. Both strengths are available in containers of 30 capsules.

Bibliography continued from page 103-F. F. Goodwin, M.D., M.R.C.P.

BALL, K. (1954), Lancet, i, 1162.

BELL, A. L. L., Jr., SMITH, C. N. and ANDREAE, E. (1955), Amer. F. Med., 18, 536.

BELT, T. H. (1939), Brit. Heart Y., X, 283.

BESTERMAN, E. M. M. (195I), Brit. med. f., ii, 205.

BORDLEY, J. E., CAREY, R. A., HARVEY, A. M., HOWARD J. E., KATTUS, A. A., NEWMAN, E' V. and WINKEN WERDER, W. L. (1949), Bull. ₹ohns Hopk. Hosp., 85, 396.

BOUTOURLINE-YOUNG, $H$. J. and WHITTENBERGER, J. L. (1951), Ұ. clin. Invest., 30, 838. Brit. med. Э., (1954), ii, 457.

CAMERINI, F., GOODWIN, J. F. and ZOOB, M. (1955), Brit. Heart $\mathcal{F}$., in press.

COUNIHAN, T. B., EVANS, B. M. and MILNE, M. D. (1954), Clin. Sci., 13,583 .

DALEY, R. (1945), Brit. Heart F., 7, ror.

DAVIES, C. E. and McKINNON, J. (1949), Lancet, ii, 883.

DAVIES, L. G., GOODWIN, J. F. and VAN LEUVEN, B. D. (1954), Brit. Heart $\mathcal{f}$., 16, 440 .

DONALD, K. W. (1953), Lancet, i, 495.

DRESDALE, D., SCHULTZ, M. and MICHTOM, R. J. (1951), Amer. F. Med., 11, 686.

ECKENHOFF, J. E., ELDER, J. D., Jr. and KING, B. D. (1952), • Amer. F. med. Sci., 223, 191.

ELMES, P. C., KNOX, K. and FLETCHER, C. M. (1953), Lancet, ii, 903 .

FERRER, M. I., HARVEY, R. M., CATHCART, R. T., WEBSTER, C. A., RICHARDS, D. W., Jr. and COURNAND, A. (1950), Circulation, $\mathrm{x}, 16 \mathrm{r}$.

FLETCHER, C. M. (1955), Personal communication.

FLINT, F. J. (1954), Lancet, ii, 5i.

FOWLER, N. O., WESTCOTT, R. N., HAUENSTEIN, V. D., SCOTT, R. C. and McGUIRE, J.' (1950), f. clin. Invest, 29, 1387.

GALDSTON, M., WEISENFELD, S., BENJAMIN, B. and ROSENBLUTH, M. B. (195I), Amer. Э. Med., 10, 166.

GANS, B. (1954), Lancet, i, roI I.

GRAY, F. D., Jr., WILLIAMS, M. H., Jr. and GRAY, F. G. (1952), Amer. Heart Y., 44, 517.
HARVEY, R. M., FERRER, M. I. and COURNAND, A. (I) Circulation, 7, 932.

HARVEY, R. M., FERRER, M. I., RICHARDS, D. W., Jr. and COURNAND, A. (1951), Amer. Ұ. Med., 10, 719.

HOWARTH, S., McMICHAEI, J. and SHARPEY-SCHAFER E. P. (1947), Clin. Sci., 6, 187 .

KILPATRICK, G. S. and OLDHAM, P. D. (1954), Brit. med. ii, 385. Lancet (1953), ii, 976.

McMICHAEL, J. (1948), Edinb. nied. F., 55, 65.

MAY, J. R. (1953), Lancet, ii, 899.

MOUNSEY, J. P. D. RITZMANN, L. W. and SELVERSTONE

N. J. (1952), Brit. Heart F., 14, 442.

MOUNSEY, J. P. D., RITZMANN, L. W., SELVERSTONES N. J., BRISCOE,' W. A. and MCLEMÖRE, G. A. (1952) Ibid., 14, 153.

NADELL, J. (1953), f. clin. Invest., 32, 622.

PALMER, K. N. V. (1954), Brit. med. F., i, 1473.

SAVIDGE, R. S. and BROCKBANK, W. (1954a), Lancet, ii, 889 SAVIDGE, R. S. and BROCKBANK, W. (1954b), Ibid., 893.

SCOTT, R. W. (1920), Arch. intern. med., 26, 544.

SHARPEY-SCHAFER, E. P. (1946), Brit. med. F., ii, 888.

SIMPSON, T. (1954), Ibid., x, 297.

STONE, D. J., SCHWARTZ, A., NEWMAN, W. FELTMAN J. A. and LOVELOCK, F. J.'(1953), Amer. $\mathcal{F}$. Med., 14, 14. I WEST, J. R., MCCLEMENT, J. H., CARROLL, D., BLISS H.' A., KUSCHNER, M., RICHARDS, D. W., Jr. ant COURNAND, A. (1951), Ibid., 10, 156.

WESTLAKE, E. K. (1954), Brit. med. F., il, 1012.

WESTLAKE, E. K. and KAYE, M. (1954), Ibid., $1,302$.

WESTLAKE, E. K., SIMPSON, T. and KAYE, M. (1955), Quar? F. Med., 24, 155 .

WHITESIDE, J. D. and COIGLEY, M. H. (1952), Lancet, il, 1037 WILKINS, R. W. MIXTER, G. Jr. STANTON, J. R. anE LITTER, J. (1952), New Engl. भ. Med., 246, 360.

WISHART, M. and ISAACS, B. (1955), Lancet, i, 995.

WOLFF, F. W. (1954), Ibid., ii, 72.

WOLFF, L. (1952), Circulation, 6, 768.

WOOD, P. (1947), Brit. Heart. F., 9, 308.

WOOD P. (I950), British Encyclopaedia of Medical Practice, and e Vol. 3, p.657, London: Butterworth. 